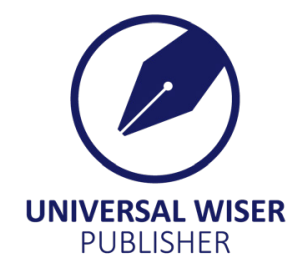

\title{
Synthesis of Nanocomposite (CAU-10-H) Thin-Film Nanocomposite (TFN) Membrane for Removal of Color from the Water
}

\author{
Ehsan Kianfar ${ }^{1,2}$, H. Mazaheri ${ }^{1}$ \\ ${ }^{1}$ Department of Chemical Engineering, Arak Branch, Islamic Azad University, Arak, Iran \\ ${ }^{2}$ Young Researchers and Elite Club, Gachsaran Branch, Islamic Azad University, Gachsaran, Iran \\ E-mail: h-mazaheri@iau-arak.ac.ir
}

\begin{abstract}
In this study, the synthesized is nanocomposite (CAU-10-H) all samples were characterized by Scanning electron microscope (SEM), Transmission electron microscopy (TEM), X-ray diffraction (XRD), and Fourier-transform infrared spectroscopy (FTIR). The (nanofiltration (NF)) membranes were constructed by interfacial polymerization of 1, 3, 5-benzenetricarbonyl trichloride and Piperazine using different loading of (CAU-10-H) $(0.250,0.50 \% \mathrm{wt}$.). The removal of color from the water by membranes with Solution filtration showed that the membrane containing $0.50 \%$ wt. of the nanocomposite (CAU-10-H) had the best. The removal of color from the water flux rejection of the thin-film nanocomposite (TFN) membrane which the removal of color from the water flux was $25.45 \mathrm{~L} / \mathrm{m} 2 . \mathrm{hr}$ and Tirmethylcyclohexan-1-one rejection was $99.35 \%$ at 6 bar.
\end{abstract}

Keywords: thin-film nanocomposite (TFN), nanofiltration (NF), metal-organic framework, removal color

\section{Introduction}

Membrane separation methods have high efficiency, low cost and less side effects than other separation methods such as distillation, evaporation, adsorption, ion exchange, etc. ${ }^{[1-5]}$, due to these advantages and the high separation of colored compounds from water. This laboratory sample is expected to use the results of this research in color-related industries such as dyeing, textiles, automotive, food industry or any industry that produces stained wastewater by completing experiments ${ }^{[-10]}$. The wastewater from Raze paint industry is one of the sewage that is not easy to clean. These wastewaters contain significant amounts of organic dyes ${ }^{[11-13]}$. The presence of organic dyestuffs in industrial wastewater, due to the prevention of light penetration into the water, disrupting the photosynthesis process, reducing the oxygen transfer to inside the water and the solubility of the gases and their toxic effects, they cause irreparable damage to the environment. Therefore, the treatment of colored wastewater from textile wastewater is necessary before they are ejected into the environment ${ }^{[14-20]}$. Biological purification processes are generally effective for the removal of oxygen required for biochemical and suspended solids ${ }^{[21-22]}$. For the hijack, the color of this wastewater is not very effective because the colored compounds have robust and complex structures that cause the rate of biodegradation of the colors to slow down, which has led to the use of other methods such as membrane filtration ${ }^{[23-25]}$. Membrane filtration is a physical separation process ${ }^{[26-28]}$. Where the driving force is the pressure difference on both sides of the membrane ${ }^{[29-31]}$. Separation in this type of process is performed based on the particle size and molecular characteristics of the membrane, which acts as a physical barrier and divides the flow into two parts ${ }^{[32-34]}$. These membranes are usually made of synthesized polymers or minerals, and to isolate proteins, the removal of colloid materials, food industry, dairy, pharmaceuticals, industrial wastes, and valuable particle separation is used ${ }^{[35-39]}$. Due to the rapid development of membrane technology, there is a strong interest in the development of high-performance membranes to meet current and future requirements and challenges ${ }^{[40]}$. Some materials, including carbon nanotubes, graphene, metal-organic frameworks (MOFs), covalent-organic materials ${ }^{[41-48]}$, zeolites ${ }^{[49-50]}$, and double-layered hydroxide, have considerable potential for high-performance membranes due to their high potential ${ }^{[1-54]}$. The presence of color in water results from the presence of natural colorants or the entry of industrial wastewater into the water. Synthetic paints are common pollutants in industrial wastewater. Textile and dyeing industries are the most important consumers of synthetic paints and chemicals for the color process. The concentration of colorants in the wastewater of these industries is lower than other chemicals, but the color intensity of this sewage

Copyright (C)2020 Ehsan Kianfar, et al.

DOI: https://doi.org/10.37256/fce.122020544

This is an open-access article distributed under a CC BY license

(Creative Commons Attribution 4.0 International License)

https://creativecommons.org/licenses/by/4.0/ 
is high due to the presence of dye remaining in the wastewater of these industries, which are even visible at very low concentrations ${ }^{[55-57]}$. The characteristics of colored sewage produced in the textile industry, brightness, visibility of color at very low concentrations, diverse chemical structures, resistance to light and chemicals, and variable $\mathrm{pH}$ domains that make them resistant to biodegradation. Some types of colors, especially azo paints, maybe carcinogens and mutated ${ }^{[28-29]}$. This paper aimed to use an nanofiltration (NF) membrane made of (CAU-10-H) Nano composition polyamide layer with Nano composition (CAU-10-H) of metal-organic framework (MOF) to improve the function of the thin-film nanocomposite (TFN) membrane. The yield membrane for removal of color from the water was tried to be enhanced by adding nanocomposite (CAU-10-H) to the alloy membrane (TFN) and then improve a membrane structure.

\section{Experimental}

\subsection{Materials}

Piperazine (PIP, > 99\%, Merck), n-hexane (>99\%, Merck) and 1, 3, 5-benzenetricarbonyl trichloride (TMC, $>98 \%$, Merck) were the monomers used for the synthesis of PA selective layer for TFC membranes. Aluminium nitate $\left(\mathrm{Al}\left(\mathrm{N}_{3} \mathrm{O}\right)_{3.9 \mathrm{H}_{2} \mathrm{O}}, 98 \%\right.$ Merck), Isophthalic acid $\left(\mathrm{C}_{8} \mathrm{H}_{6} \mathrm{O}_{4}, 99 \%\right.$ Merck) and isophthalic acid (98\%, Merck) were used for synthesizing metal-organic frameworks (MOFs) nanoparticles. Tirmethylcyclohexan-1-one (98\%, Sigma). Were used for preparing salt solution at different concentrations nanofiltration (NF) experiments.

\subsubsection{Iso phthalic acid / aluminum nitrate nanocomposite synthesis}

$0.14 \mathrm{~g}$ of Iso-phthalic acid, $0.65 \mathrm{~g}$ of aluminum nitrate and $10 \mathrm{ml}$ of the distilled water were placed in a hydrothermal reactor and heated in a furnace at $220^{\circ} \mathrm{C}$ for 50 hours. Now, the precipitated material is separated with some distilled water by centrifugal and drying the considered nanoparticles at $150^{\circ} \mathrm{C}$ for 2 hours. For better activation, the nanoparticles were re-heated at $220^{\circ} \mathrm{C}$ for a period of 2 hours.

\subsection{Membrane fabrication}

The nanocomposite(CAU-10-H) using $2 \%$ Piperazine with various amounts of nanocomposite(CAU-10-H) $(0.250,0.50)$ for 2 min and $0.1 \% 1,3,5$-benzenetricarbonyl trichloride as the organic solution for 1 min. Depending on the nanocomposite(CAU-10-H) loading these membranes are denoted as (Nanofiltration), (Nano filtration-1), and (Nanofiltration-2) respectively.

\subsection{Membrane performance}

Figure 1 shows the Nano filtration system setup. The water flux (J) and the water permeability (A) of the membranes were calculated by Equation (1) and (2), respectively.

$$
J=\frac{\Delta V}{A_{m} \cdot \Delta t}
$$

Where $\mathrm{A}_{\mathrm{m}}$ is effective membrane area $\left(33 \mathrm{~cm}^{2}\right)$, and $\Delta \mathrm{V}$ is permeate volume $(\mathrm{ml}), \Delta \mathrm{t}$ is time and $\Delta \mathrm{P}$ is transmembrane pressure difference. To evaluate salt rejection, $\mathrm{R}(\%)$ of the membrane, the following equation was employed.

$$
R=\left(1-\frac{C_{p}}{C_{f}}\right) \times 100
$$

Where $\mathrm{C}_{\mathrm{f}}$ and $\mathrm{C}_{\mathrm{p}}$ are the salt concentrations in the feed and permeate solution, respectively. 


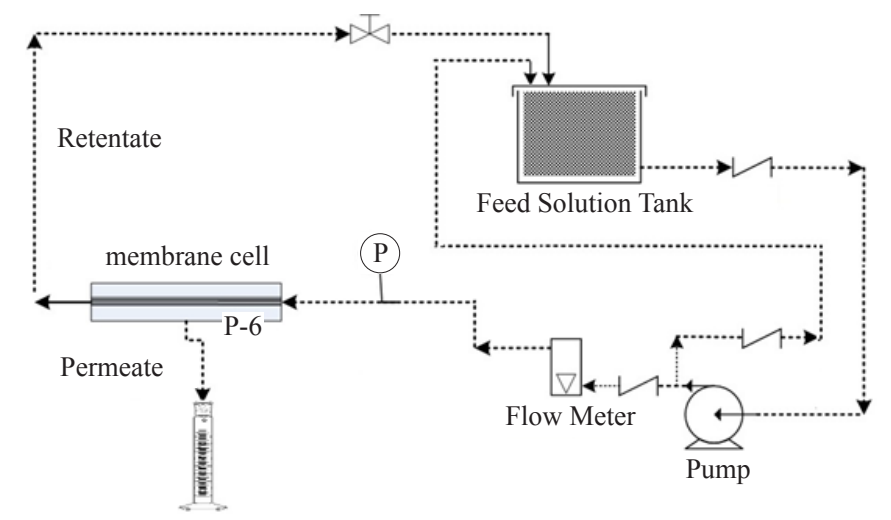

Figure 1. Schematic diagram of Nano filtration

\section{Results and discussion}

\subsection{Membranes characterization}

\subsubsection{XRD analysis}

Figure 2 indicates the spectra associated with XRD analysis for nanocomposite (CAU-10-H). As can be seen, the spectrum has some prominent peaks associated with nanocomposite (CAU-10-H). The relative crystalline mode of this catalyst was calculated according to a reference, considering prominent peaks within angles of $10-50^{\circ}$ sharp peaks at 17 , $18,20,22,23.1,25$ and 29 are the most predominant peaks for calcined nanocomposite (CAU-10-H). The crystallite sizes determined based on the Scherrer's equation (Eq. 3). In this equation, D is crystallite size (nm), $\lambda$ is X-ray wavelength approximately equal to $1.541 \mathrm{~A}^{\circ}, \beta$ is the line width at half the maximum intensity (Full width at half maximum (FWHM)), and $\theta$ is bragg angle. Indeed, to determine the crystallite size of catalysts, the XRD diffraction patterns is used and the Highscore plus software is capable to calculate this parameter.

$$
\mathrm{D}=(0.9 \lambda) / \beta \cos \theta
$$

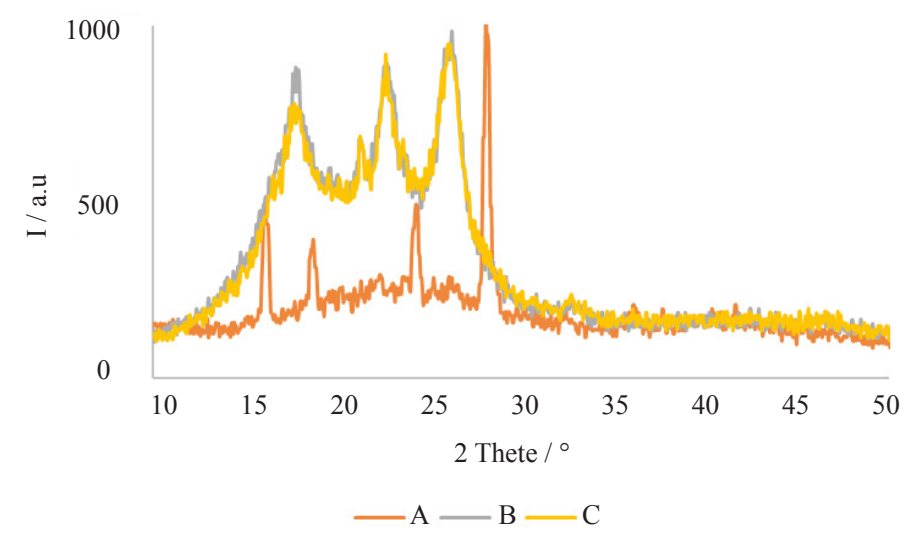

Figure 2. XRD patterns of the nanocomposite (CAU-10-H), A (Nanofiltration), B (Nano filtration-1), and C (Nanofiltration-2)

\subsubsection{Fourier-transform infrared spectroscopy (FTIR) analysis}

The FTIR spectra of control and various loading of metal-organic framework (MOF) membrane are shown in Figure 3. Carbonyl stretching vibrations of amide appears at $1620 \mathrm{~cm}-1$. The peak at $1576 \mathrm{~cm}-1$ corresponding to in-plane N-H bending and C-N stretching vibrations and amide functionalities show two bands at 1415 and $1483 \mathrm{~cm}-1$. High intensity bands at 699 and $718 \mathrm{~cm}-1$, attributed to C-H-out-of-plane vibrations of the aromatic ring. The above vibrations confirmed the polymerization occurred between PIP and TMC monomers and the active skin layer of nanofiltration (NF) membrane was polyamide containing different loading of metal-organic framework (MOF) and obviously showed the unchanged structure of membrane under softening conditions. 


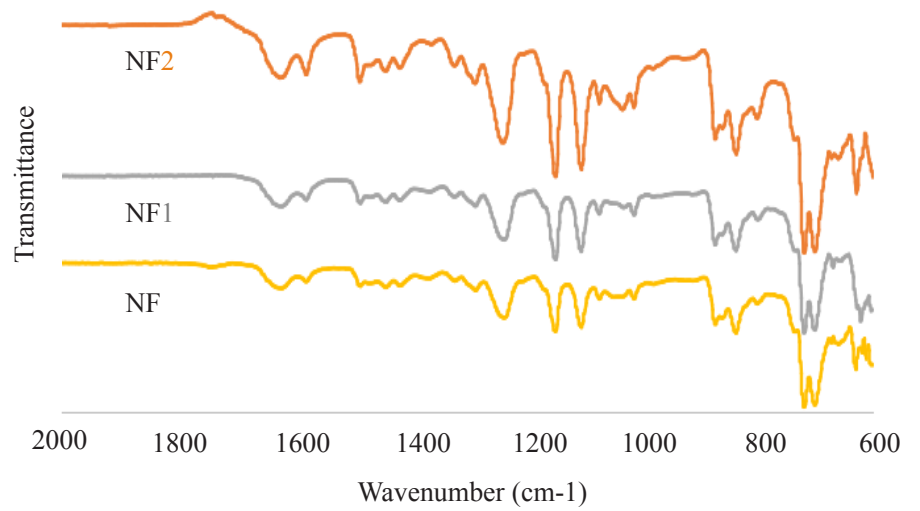

Figure 3. FTIR patterns of the nanocomposite (CAU-10-H), A (Nanofiltration), B (Nano filtration-1), and C (Nanofiltration-2)

\subsubsection{SEM, EDX, TEM analysis}

SEM was used to describe the morphology of the membranes. In Figure 4 the surface morphology of nanofiltration (NF) membranes is shown. Top surface image of the neat membrane (A) and various nanocomposite (CAU-10-H), loading (B to C) possess a nodular surface structure which conforms to the XRD and EDX results ${ }^{[54]}$. These images reveal that the surface layer of the membrane is properly coated and interracially polymerized. SEM pictures of nanocomposite (CAU10-H), membranes showed partially changed morphology compared to the reference membrane with no metal-organic frameworks (MOFs) addition. Micro voids present in nanofiltration (NF) (Figure 4a, 4b, 4c) were suppressed as increasing in nanocomposite (CAU-10-H), loadings ${ }^{[55]}$. The presence of nanoparticles at the surface of a membranes was investigated by EDX, as shown in Figure 5. Presence of element Al with various intensity confirm the loading of different amount of iso-phthalic acid / aluminium nitrate nanoparticles on the polymeric layer in $\mathrm{b}$ and $\mathrm{c}$ membranes. This result suggests that the surface of the membrane is covered by various loading of iso-phthalic acid / aluminium nitrate, which is in agreement with other achieved analyses. Figure 6 shows the TEM of nanocomposite (CAU-10-H), Morphology and surface roughness of the nanocomposite (CAU-10-H), were characterized. The particles have no spherical Piped and their surfaces have a porous structure. As a result, it can be expected that nanocomposite (CAU-10-H) have a remarkable antiseptic effect compared to common non-porous types.
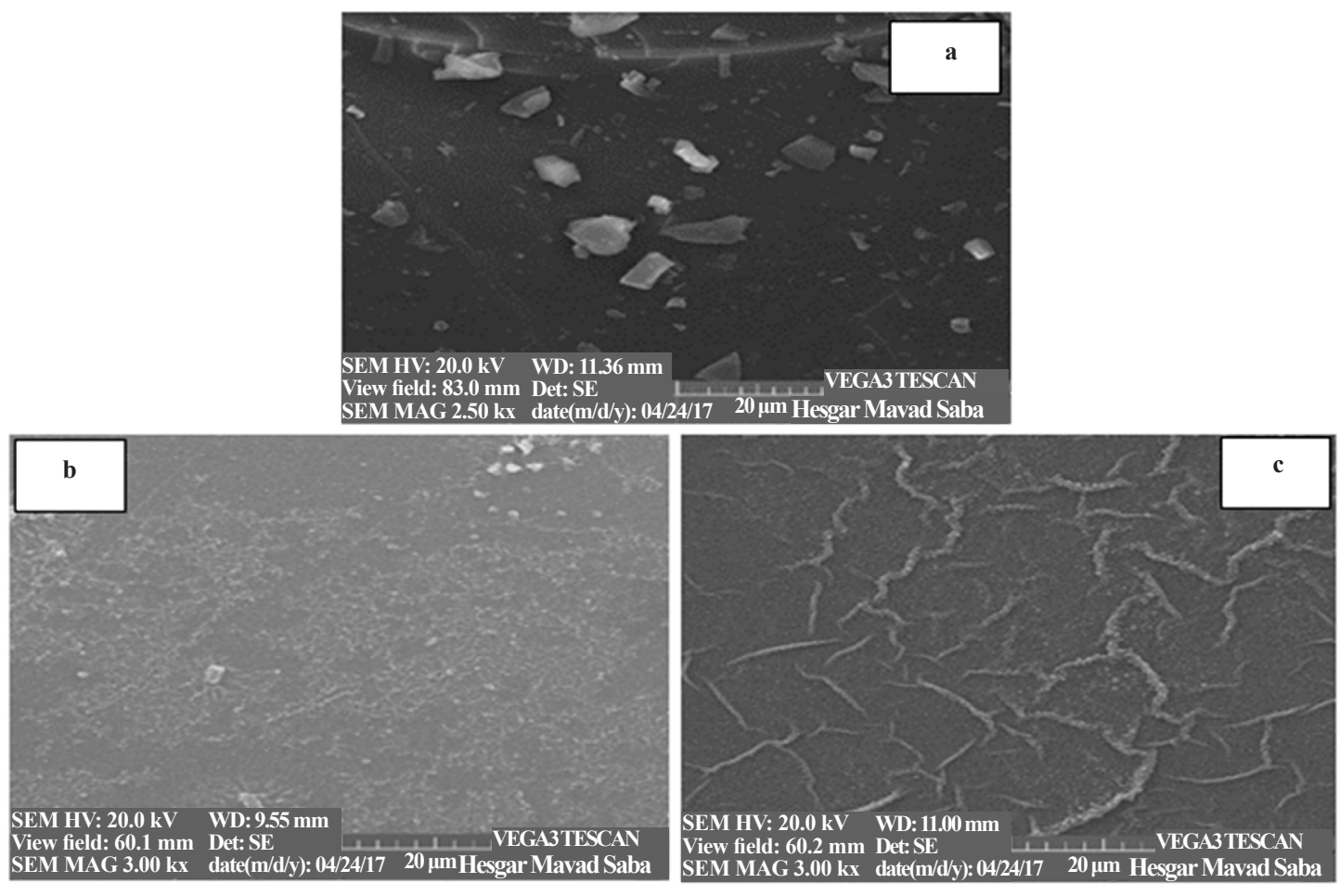

Figure 4. SEM images of the nanocomposite (CAU-10-H), A (Nanofiltration), B (Nano filtration-1), and C (Nanofiltration-2) 

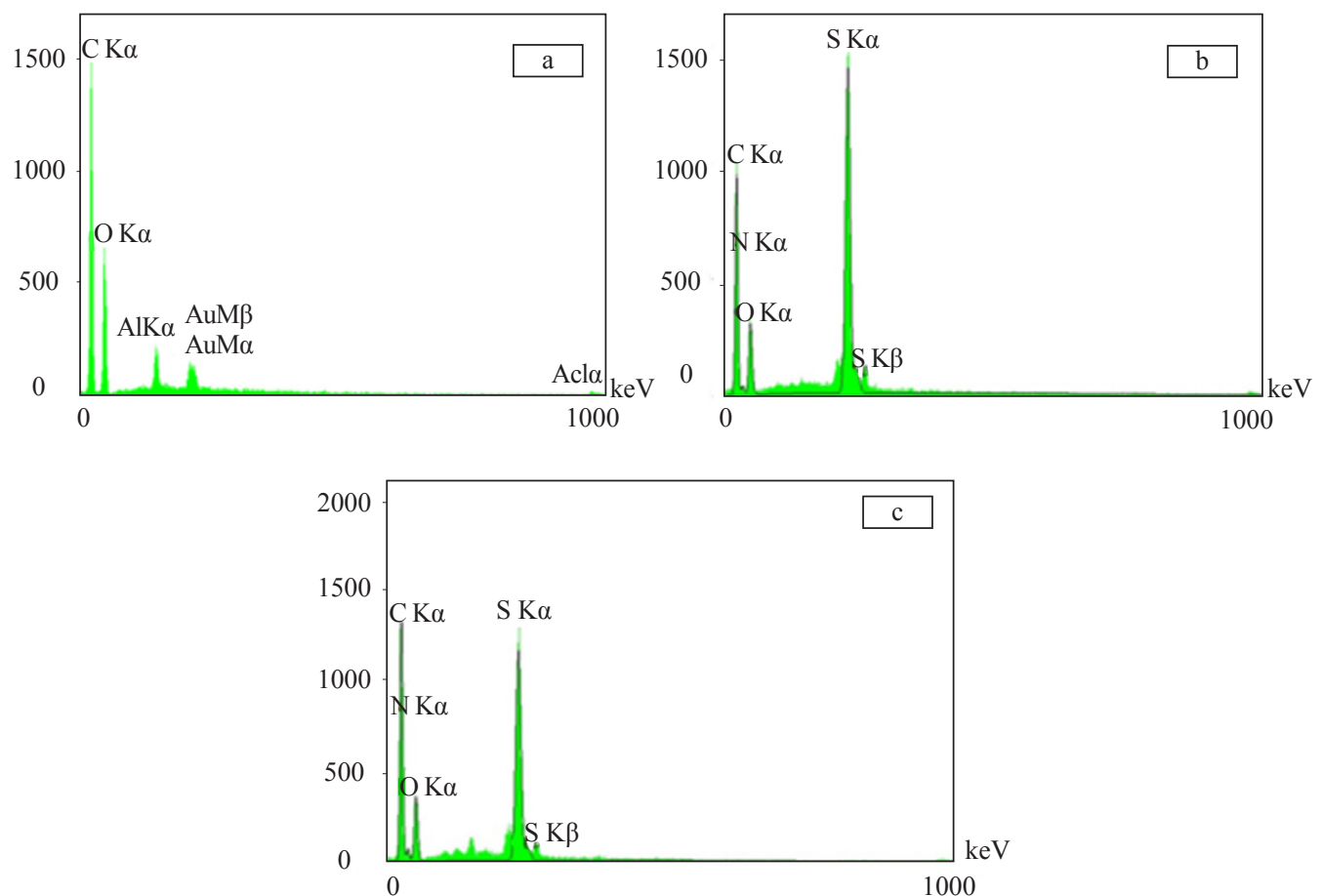

Figure 5. EDX images of the nanocomposite (CAU-10-H), A (Nanofiltration), B (Nano filtration-1), and C (Nano filtration-2)
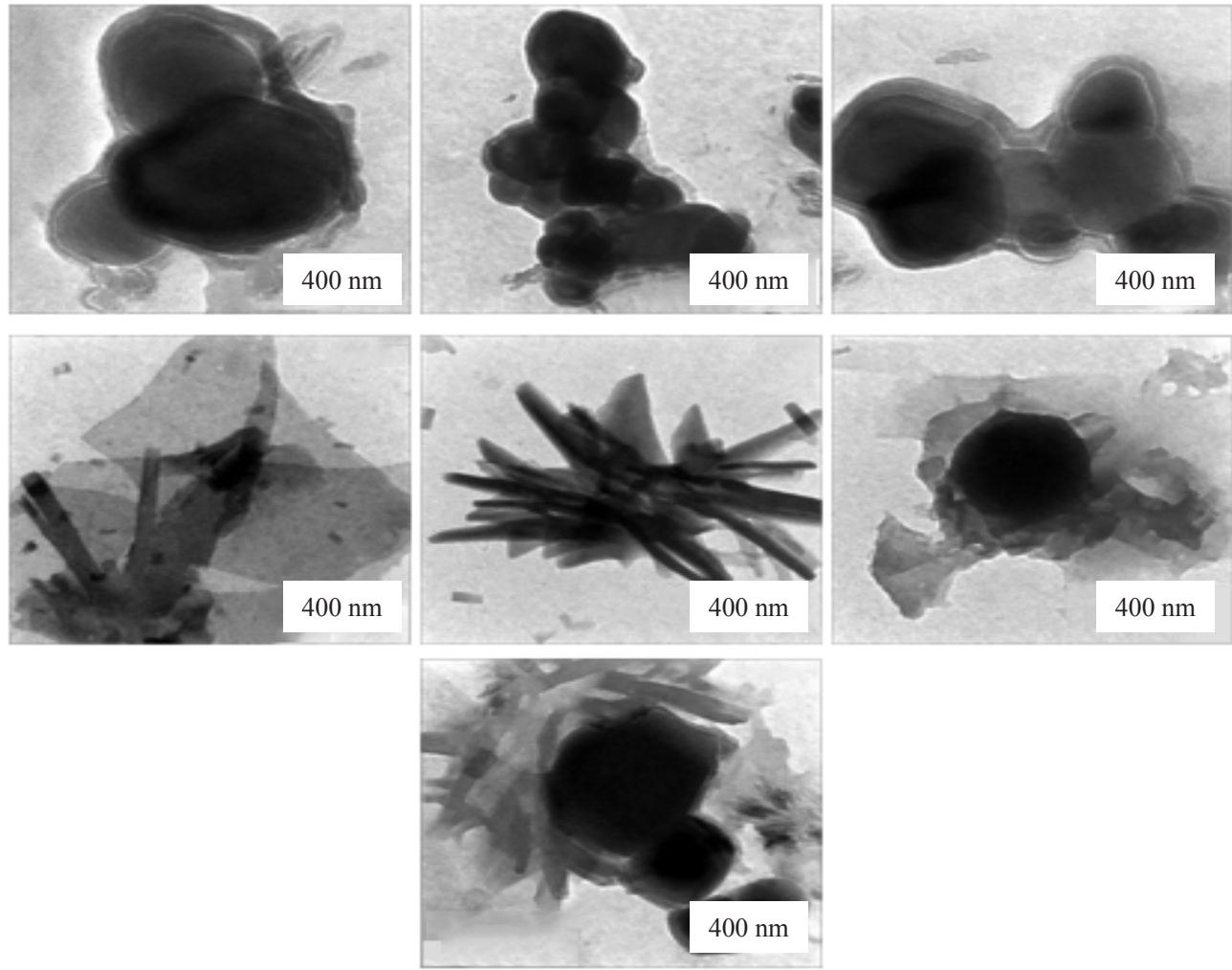

Figure 6. A TEM image of nanocomposite (CAU-10-H) 


\subsubsection{Preparation of nanocomposite membranes}

The lining method has been used to make nanocomposite membrane. For this purpose, first, the iso-phthalic acid / aluminum nitrate nanocomposite in dimethylacetamide solvent were added to the solvent in different weight percentages of the total weight of the polymer and were stirred well at room temperature for $1 \mathrm{~h}$ until the homogenous solution of nanoparticle-solvent was obtained.

Table 1. Physical properties of iso-phthalic acid / aluminum nitrate nanocomposite nanoparticles

\begin{tabular}{cc}
\hline Typical properties & iso-phthalic acid / aluminum nitrate nanocomposite \\
\hline Specific surface area (BET) & $190 \mathrm{~m}^{2} / \mathrm{g}$ \\
Particle size & $5-10 \mathrm{~nm}$ \\
Density & $3.26 \mathrm{~g} / \mathrm{mL}$ \\
Color & White \\
Purity (based on metal) & $>99.9 \%$ \\
\hline
\end{tabular}

\section{Results nanocomposite (CAU-10-H) the removal of color from the water}

Results nanocomposite (CAU-10-H) the removal of color from the water flux rejection is completely discussed in this study. The water flow values of the membranes containing the different amounts of Nano synthesis are shown in Figure 7. The diagram shows that membranes with higher nanoparticles have lower water flow. However, as the test time progresses, a slight decrease in flow is observed. This is the main reason for promoting hydrophobicity and observing less flow in the cell membrane at 0.250 Nano percent. In fact, the presence of inorganic nanoparticles increases the solvent-insoluble exchange rate during the phase inversion process, which leads to the formation of more holes in the membrane. This is the main reason for promoting hydrophobicity and observing less flow in the cell membrane at 0.250 Nano percent. Compared to membranes that use non-porous particles, Membranes that contain a higher percentage of Nano have less water flow but more purity, but by reducing, the amount of Nano more than the amount of water but water that is more pure flows and is almost twice the same under laboratory conditions. After the first 30 minutes, the amount of water flow reached 145 and the amount remained constant until the end, and the amount of efficiency increased from $72 \%$ to $69 \%$ and remained almost constant in the last 30 minutes. The amount of water flow and efficiency are shown in Figure 6. The removal of color from the water flux in all measurements faintly increased with increasing time because of the enhanced driving force for permeation of water. Surviving of all diagrams in Figure 8. Reveal that as the nanocomposite (CAU-10-H) content in the membrane increases, the removal of color from the water flux also increases. The removal of color from the water flux rejection of the TFN membrane, which the removal of color from the water flux was $25.45 \mathrm{~L} / \mathrm{m} 2 . \mathrm{hr}$ and Tirmethylcyclohexan-1-one rejection was $99.35 \%$ at 6 bar.

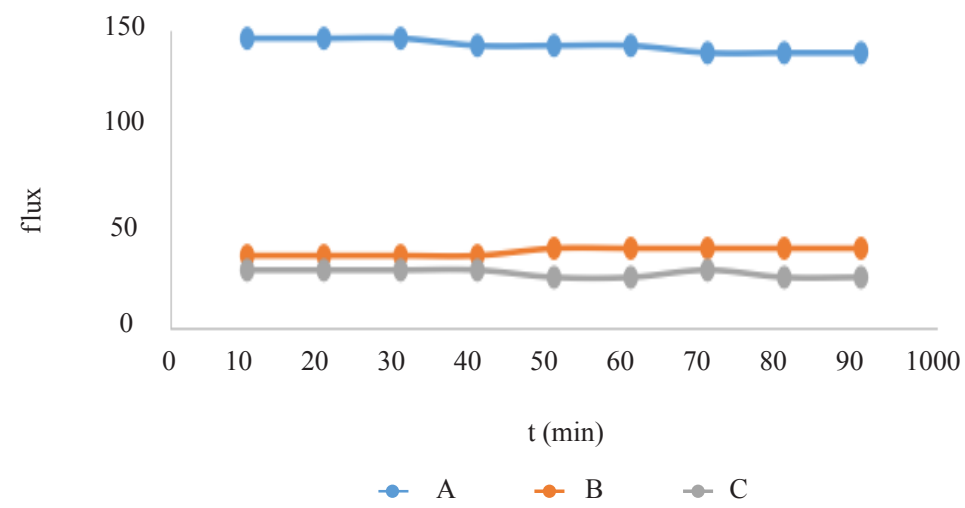

Figure 7. Flux changes against time for the nanocomposite (CAU-10-H), A (Nanofiltration), B (Nano filtration-1), and C (Nanofiltration-2) 


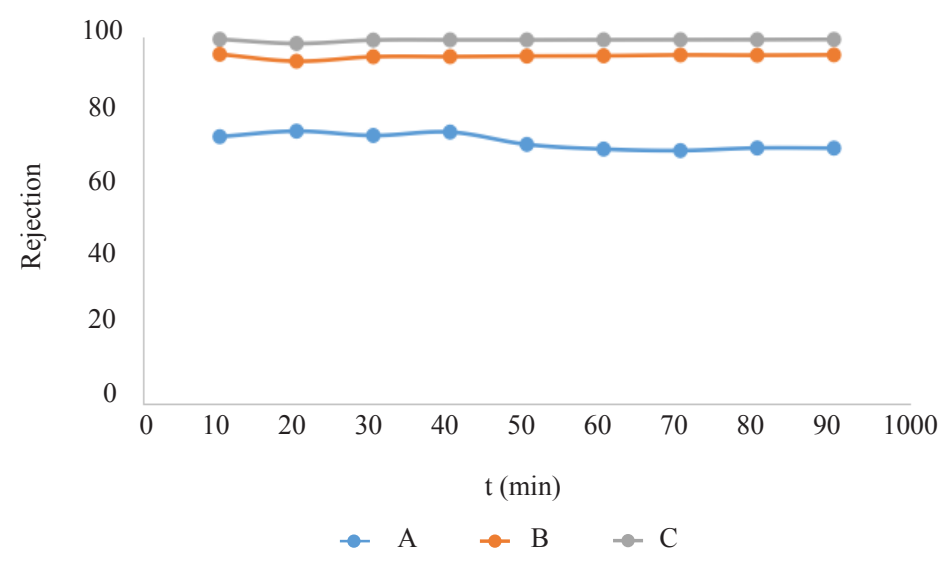

Figure 8. Rejection changes against time for the nanocomposite (CAU-10-H), A (Nanofiltration), $B$ (Nano filtration-1), and C (Nanofiltration-2)

\section{Conclusion}

In this work, the synthesized is nanocomposite (CAU-10-H) all samples were characterized by SEM, TEM, XRD, and FTIR. The Nano filtration membranes were constructed by interfacial polymerization of TMC and Pip using different loading of $(\mathrm{CAU}-10-\mathrm{H})(0.250,0.50)$. All tests were carried out at 6 bar and the results of the deep investigation showed that with increasing the amount of nanocomposite phthalic acid / aluminum nitrate (CAU-10-H), its performance was improved. The removal of color from the water flux rejection of the thin-film nanocomposite (TFN) membrane which the removal of color from the water flux was $25.45 \mathrm{~L} / \mathrm{m} 2 . \mathrm{hr}$ and Tirmethylcyclohexan-1-one rejection was $99.35 \%$ at 6 bar.

\section{Nomenclature}

MOF: metal-organic framework

CAU-10-H: isophthalic acid / aluminum nitrate

TFN: thin-film nanocomposite

NF: nanofiltration

(Nano filtration-1): 0.250 isophthalic acid / aluminium nitrate

(Nano filtration-2): 0.50 isophthalic acid / aluminium nitrate

SEM: Scanning electron microscope

TEM: Transmission electron microscopy

XRD: X-ray diffraction

FTIR: Fourier-transform infrared spectroscopy

PFD: Process flow diagram

FWHM: Full width at half maximum

DEX: Samsung DeX

TMC: 1, 3, 5-benzenetricarbonyl trichloride

PIP: Piperazine

\section{Reference}

[1] Rahimpour. UV photo-grafting of hydrophilic monomers onto the surface of nanoparticles porous PES membranes for improving surface properties. Desalination. 2011; 265: 93-101.

[2] M. Padaki, A. M. Isloor, R. Kumar, et al. Matsuura, synthesis, characterization and desalination study of composite NF membranes of novel poly [(4-aminophenyl) sulfonyl] butanediamide (PASB) and methyalated poly [(4-aminophenyl) sulfonyl] butanediamide (mPASB) with polysulfone (PSf). Journal of Membrane Science. 2013; 428: 489-497.

[3] Padaki, M., et al. Antifouling properties of novel PSf and $\mathrm{HNT} / \mathrm{TiO}_{2}$ composite membrane and study of effect of the flow direction on membrane washing. Desalination. 2015; 362: 141-150.

[4] D. Emadzadeh, et al. The potential of thin film nanoparticlescomposite membrane in reducing organic fouling in forward osmosis process. Desalination. 2014; 348: 82-88.

[5] Arsuaga, J. M., et al. Influence of the type, size, and distribution of metal oxide particles on the properties of nanopar- 
ticlescomposite ultrafiltration membranes. Journal of Membrane Science. 2013; 428: 131-141.

[6] G. Zhang, et al. Novel polysulfone hybrid ultrafiltration membrane prepared with TiO 2-g-HEMA and its antifouling characteristics. Journal of Membrane Science. 2013; 436: 163-173.

[7] A. Ramous, et al. The effect of modified $\mathrm{TiO}_{2}$ nanoparticles particles on the polyether sulfone ultrafiltration hollow fiber membranes. Desalination. 2012; 287: 271-280.

[8] M. Salimi, V. Pirouzfar, E. Kianfar. Enhanced gas transport properties in silica nanoparticles particle filler-polystyrene nanoparticles composite membranes. Journal of Colloid and Polymer Science. 2017; 295: 215-226.

[9] M. Salimi, V. Pirouzfar, E. Kianfar. Novel nanoparticles composite membranes prepared with PVC / ABS and silica nanoparticles particles for $\mathrm{C}_{2} \mathrm{H}_{6} / \mathrm{CH}_{4}$ separation. Journal of Polymer Science, Series A. 2017; 89: 566-574.

[10] D. Emadzadeh, et al. A novel thin film nanoparticles composite reverse osmosis membrane with superior anti-organic fouling affinity for water desalination. Desalination. 2015; 368: 106-113.

[11] L. Mingliang, et al. Fabrication of SPES / nanoparticles- $\mathrm{TiO}_{2}$ composite ultrafiltration membrane and its anti-fouling mechanism. Chinese Journal of Chemical Engineering. 2011; 19(1): 45-51.

[12] H. Chen, J. Zhao, J. Wu, et al. Selective desorption characteristics of halloysite nanoparticles tubes for anionic azo dyes. RSC Advances. 2014; 4(30): 15389-15393.

[13] C. Chen, W. Cai, M. Long, et al. Synthesis of visible-light responsive graphene oxide $/ \mathrm{TiO}_{2}$ composites with $\mathrm{p} / \mathrm{n}$ heterojunction. ACS nanoparticles. 2010; 4(11): 6425-6432.

[14] E. Celik, H. Park, H. Choi, et al. Carbon nanoparticles tube blended polyether sulfone membranes for fouling control in water treatment. Water research. 2011; 45(1): 274-282.

[15] N. Bui, et al. Electrospun nanoparticles fiber supported thin film composite membranes for engineered osmosis. Journal of Membrane Science. 2011; 385: 10-19.

[16] Ehsan Kianfar. (PVC / ABS) and Nanocomposite (CAU-10-H) Composite Membrane for Separation of $\mathrm{C}_{2} \mathrm{H}_{6}$ from $\mathrm{CH}_{4}$. Fine Chemical Engineering. 2020; 1(2): 58-67. Available from: https://doi.org/10.37256/fce.122020476.

[17] C. Boo, et al. Fouling control in a forward osmosis process integrating seawater desalination and wastewater reclamation. Journal of Membrane Science. 2013; 444: 148-156.

[18] E. Kianfar, et al. An experimental study on absorption / stripping $\mathrm{CO}_{2}$ using Mono-ethanol amine hollow fiber membrane contactor. Journal of the Taiwan Institute of Chemical Engineers. 2017; 80: 954-962.

[19] E. Kianfar. Production and identification of vanadium oxide nanotubes. Indian Journal of Science and Technology. 2015; 8(S9): 455-464.

[20] Ehsan Kianfar. Recent advances in synthesis, properties, and applications of vanadium oxide nanotube. Microchemical Journal. 2019; 145: 966-978.

[21] S. Rajesh, S. Senthilkumar, A. Jayalakshmi, et al. Preparation and performance evaluation of poly (amide-imide) and $\mathrm{TiO}_{2}$ nanoparticles impregnated polysulfone nanofiltration membranes in the removal of humic substances. Colloids and Surfaces A: Physicochemical and Engineering Aspects. 2013; 418: $92-104$.

[22] B. Rajaeian, A. Rahimpour, M. O. Tade, et al. Fabrication and characterization of polyamide thin film nanocomposite (TFN) nanofiltration membrane impregnated with $\mathrm{TiO}_{2}$ nanoparticles. Desalination. 2013; 313: 176-188.

[23] X. Cao, et al. Effect of $\mathrm{TiO}_{2}$ nanoparticle size on the performance of PVDF membrane. Applied Surface Science. 2006; 253(4): 2003-2010.

[24] T. Cath, et al. Forward osmosis: Principles, applications, and recent developments. Journal of membrane science. 2006; 281(1):70-87.

[25] T. Cath, et al. A multi-barrier osmotic dilution process for simultaneous desalination and purification of impaired water. Journal of Membrane Science. 2010; 362(1): 417-426.

[26] E. Celik, et al. Carbon nanotube blended polyether sulfone membranes for fouling control in water treatment. Water Research. 2011; 45(1): 274-282.

[27] J. C. Crittenden, et al. Water Treatment: Principles anddesign. 2nd ed. John Wiley \& Sons Inc; 2005.

[28] S.S. Madaeni, E. Enayati, V. Vatanpour. Separation of nitrogen and oxygen gases by polymericmembrane embedded with magnetic nano-particle. Polymers for Advanced Technologies. 2011; 22: 2556-2563.

[29] P. Jian, H. Yahui, W. Yang, et al. Preparation of polysulfone- $\mathrm{Fe}_{3} \mathrm{O}_{4}$ composite ultrafiltration membrane and its behavior inmagnetic field. Journal of Membrane Science. 2006; 284: 9-16.

[30] Y. Mansourpanah, S. S. Madaeni, A. Rahimpour, et al. Fabrication new PES-based mixed matrix nanocomposite membranes using polycaprolactone modified carbon nanotubes as the additive: Property changes and morphological studies. Desalination. 2011; 277: 171-177.

[31] S. J. Miller, W. J. Koros, D. Q. Vu. Mixed matrix membrane technology: Enhancing gasseparations with polymer / molecular sieve composites. Studies in Surface Science and Catalysis. Elsevier; 2007. p.1590-1596.

[32] A. Razmjou, J. Mansouri, V. Chen. The effects of mechanical and chemical modification of $\mathrm{TiO}_{2}$ nanoparticles on the surface chemistry, structure and fouling performance of PES ultrafiltration membranes. Journal of Membrane Science. 
2011; 378: 73-84.

[33] A. Rahimpour, M. Jahanshahi, A. Mollahosseini, et al. Structural and performance properties of UV-assisted TiO 2 deposited nano-composite PVDF/ SPES membranes. Desalination. 2012; 285: 31-38.

[34] G. D. Mehta, S. Loeb. Internal polarization in the porous substructure of a semipermeable membrane under pressure-retarded osmosis. Journal of Membrane Science. 1978; 4: 261-265.

[35] S. Loeb, L. Titelman, E. Korngold, et al. Effect of porous support fabric on osmosis through a Loeb-Sourirajan type asymmetric membrane. Journal of Membrane Science. 1997; 129: 243-249.

[36] J. R. McCutcheon, M. Elimelech. Modeling water flux in forward osmosis: Implications for improved membrane design. Aiche Journal. 2007; 53: 1736-1744.

[37] S. Zhao, P. Wang, C. Wang, et al. Thermostable PPESK / $\mathrm{TiO}_{2}$ nanocomposite ultrafiltration membrane for high temperature condensed water treatment. Desalination. 2012; 299: 35-43.

[38] X. Li, S. Zhang, F. Fu, et al. Deformation and reinforcement of thin-film composite (TFC) polyamide-imide (PAI) membranes for osmotic power generation. Journal of Membrane Science. 2013; 431: 204-217.

[39] Ehsan Kianfar, Mahmoud Salimi, Behnam Koohestani. Methanol to gasoline conversion over CuO / ZSM-5 catalyst synthesized and influence of water on conversion. Fine Chemical Engineering. 2020; 1(2): 74-81. Available from: https://doi.org/10.37256/fce.122020499.

[40] C. Y. Tang, Q. She, W. C. L. Lay, et al. Coupled effects of internal concentration polarization and fouling on flux behavior of forward osmosis membranes during humic acid filtration. Journal of Membrane Science. 2010; 354; 123133.

[41] Kianfar, E., Salimi, M., Kianfar, F. et al. $\mathrm{CO}_{2} / \mathrm{N}_{2}$ separation using polyvinyl chloride iso-phthalic acid / aluminium nitrate nanocomposite membrane. Macromolecular Research. 2019; 27: 83-89. Available from: https://doi.org/10.1007/ s13233-019-7009-4.

[42] E. Kianfar, M. Salimi, V. Pirouzfar, et al. Synthesis and modification of zeolite ZSM-5 catalyst with solutions of calcium carbonate $\left(\mathrm{CaCO}_{3}\right)$ and sodium carbonate $\left(\mathrm{Na}_{2} \mathrm{CO}_{3}\right)$ for methanol to gasoline conversion. International Journal of Chemical Engineering. 2018; 16(7): 1-7.

[43] E. Kianfar, M. Salimi, S. Hajimirzaee, et al. Methanol to gasoline conversion over CuO / ZSM-5 catalyst synthesized using sonochemistry method. International Journal of Chemical Reactor Engineering. 2019; 17(2): 1-10.

[44] E. Kianfara. Synthesis and characterization of AlPO4 / ZSM-5 catalyst for methanol conversion to dimethylether. Russian Journal of Applied Chemistry. 2018; 91(10): 1710-1720.

[45] Ehsan Kianfar. Recent advances in synthesized, properties, applications of Nano-zeolites. Journal of Sol-Gel Science and Technology. 2019; 91(2): 415-429.

[46] Ehsan Kianfar, Mahmoud Salimi, Vahid Pirouzfar, et al. Synthesis of modified catalyst and stabilization of CuO / NH4-ZSM-5 for conversion of methanol to gasoline. International Journal of Applied Ceramic Technology. 2018; 15(3): 734-741.

[47] Ehsan Kianfar. Comparison and assessment of zeolite catalysts performance dimethyl ether and light olefins production through methanol: A review. Reviews in Inorganic Chemistry. 2019; 39(3): 157-177.

[48] Ehsan Kianfar. Ethylene to propylene over zeolite ZSM-5: Improved catalyst performance by treatment with CuO. Russian Journal of Applied Chemistry. 2019; 92(7): 933-939.

[49] Ehsan Kianfar. Ethylene to propylene conversion over Ni-W/ZSM-5 catalyst synthesize. Russian Journal of Applied Chemistry. 2019; 92(8): 1094-1101.

[50] E. Kianfar. Zeolite-based catalysts for methanol to gasoline process: A review. Microchemical Journal. 2019. Available from: https://doi.org/10.1016/j.microc.2020.104822.

[51] Liu, H., Kianfar, E. Investigation the synthesis of Nano-SAPO-34 catalyst prepared by different templates for MTO Process. Catal Lett. 2020. Available from: https://doi.org/10.1007/s10562-02.

[52] Ehsan Kianfar, Saeed Hajimirzaee, Seyed Mohammad Faghih, et al. Polyvinyl chloride + nanoparticles titanium oxide Membrane for Separation of $\mathrm{O}_{2} / \mathrm{N}_{2}$. Advances in Nanotechnology. NY, USA: Nova Science Publishers, Inc.

[53] Ehsan Kianfar, Seyyed Ali Hasan Razavikia. Zeolite catalyst based selective for the process MTG: A review. Zeolites: Advances in Research and Applications. NY, USA: Nova Science Publishers, Inc.

[54] Ehsan Kianfar. Zeolites: A comparison and assessment on performance of zeolite catalyst based selective for the process methanol to gasoline: A review. Advances in Chemistry Research. NY, USA: Nova Science Publishers, Inc.

[55] Ehsan Kianfar. Synthesis of characterization Nanoparticles isophthalic acid / aluminum nitrate (CAU-10-H) using method hydrothermal. Advances in Chemistry Research. NY, USA: Nova Science Publishers, Inc.

[56] Ehsan Kianfar. Zeolites: Properties, applications, modification and selectivity. Zeolites: Advances in Research and Applications. NY, USA: Nova Science Publishers, Inc.

[57] Chengyun Gao, Jiayou Liao, Jingqiong Lu, et al. The effect of nanoparticles on gas permeability with polyimide membranes and network hybrid membranes: A review. Reviews in Inorganic Chemistry. Available from: DOI: https:// doi.org/10.1515/revic-2020-0007. 